\title{
Common Paragraph Writing Errors Made by Saudi EFL Students: Error Analysis
}

\author{
Farooq AlTameemy \\ Prince Sattam Bin Abdulaziz University, Saudi Arabia \\ Amer Daradkeh \\ Prince Sattam Bin Abdulaziz University, Saudi Arabia
}

\begin{abstract}
Relying on Error Analysis, this article presents an empirical study that scrutinizes comprehensively the types and frequencies of errors in paragraph compositions made by 80 EFL students, Preparatory Year Deanship, at Prince Sattam bin Abdulaziz University. In addition, it aims at exploring the differences between male and female students in regards to these errors as well as investigating whether or not native and nonnative English teachers affect significantly the types and frequencies of errors committed in writing. After analyzing 80 paragraphs at the sentence-level and the paragraph-level based on a particular rubric, the results reveal that the 80 students committed 1580 errors in total. At the sentence level, the subjects made 1316 errors in grammar (42.15\%), Punctuation (16.14\%), spelling (14.81\%) and capitalization $(10.19 \%)$. At the paragraph -level, the participants produced 264 errors illustrated in the following order: Errors in paragraph development $(5.13 \%)$, Errors in paragraph coherence $(4.87 \%)$, Errors in paragraph unity $(3.80 \%)$ and Errors in inconsistency of point of view (2.91\%). The results found that except for errors of grammar, there are no statistically significant differences between male and female students at the preparatory Year in Prince Sattam bin Abdulaziz University in the types of errors in paragraph writing. Moreover, the statistical analysis showed that there are statistically significant differences between university students taught by English native-speaker instructors and university students taught by non-native English instructors in some types of errors in paragraph writing i.e. errors in grammar, spelling and punctuation.
\end{abstract}

Index Terms — error analysis, paragraph writing, sentence level, paragraph level

\section{INTRODUCTION}

Writing is an important skill for learners through which they convey their ideas and thoughts clearly. As well as it is a very complex productive skill that requires thinking and cognitive processes in which it goes through different stages of pre-writing, while-writing, and post-writing. In addition, successful writing needs many overlapping aspects such as organization, punctuation, capitalization, spelling, coherence \& cohesion and others. A paragraph as the basic unit of any writing (Jayakaran, 2005) is a string of related sentences that gives one main idea. A long or short paragraph in general starts with a topic sentence that introduces the controlling idea of the whole paragraph. Then supporting sentences come to explain the main idea of the topic sentence for readers by giving ideas, details, and examples. To end the paragraph, a concluding sentence summarizes the whole idea of the paragraph. Thus, English language learners require high linguistic and cognitive competence to write a paragraph. This competence must be scrutinized to establish a well understanding of writing. With that, the committed errors form the indirect path to study the learners' competence in writing due to its abstraction.

Theoretical and practical criticism of Contrastive Analysis (CA) that claims language interference between the mother tongue and the target language is the most significant source of errors that lead to the emergence of Error Analysis (EA) that studies errors in the target language to find out other sources rather than the linguistic interference alone. Viewing errors as a sin which must be avoided, at any cost, many see these errors as a systematic deviation that takes place because the learner has not learned something and consistently get(s) it wrong (Norrish, 1983) or in other words an unsuccessful bit of language (James, 1998. P, as cited in Liu \&Wang, 2011). Corder (1967) emphasized the significance of errors in which they help teachers to know their students' progression as well as what to teach next, and errors also give linguists and applied linguists' insights about the process of language acquisition. In addition to that, learners themselves benefit from errors as they use them as a for learning and improving. Either in the first or second/foreign language acquisition, learners make errors in different aspects of the target language. They commit errors in speaking, listening, reading and also in writing especially at the paragraph level. Therefore, the integrated part of errors in the process of language acquisition /learning motivated many researchers to investigate errors by identifying, classifying, evaluating and setting remedial plans to avoid them.

EFL researchers, teachers, and learners have paid great attention to English writing especially paragraph writing beside other skills (reading, speaking, and listening). Although they have great expectations to write good English paragraph, many Saudi university students have a lot of problems in writing. For instance, the teachers of the writing course, at the PYD program, at Prince Sattam bin Abdulaziz University usually emphasize on plenty of errors that are 
committed in the paragraph writing. These teachers rigorously voice students' writing errors in syntax and lexicon, punctuation and capitalization, paragraph unity and development and paragraph coherence. In addition, the teachers of the writing course convey students' bitter complains about their lack of competence and the quality of their writings. As a result of such discussion, an idea emerged that it is important to conduct a scientific study to investigate learners' errors in paragraph writing based on Error analysis (EA) perspective in purpose to improve students' ability in English writing.

Subsequently, the current study appeared from a need to analyze the paragraph-writing outcomes of the preparatory year students at Prince Sattam bin Abdulaziz University. The main aim is to identify these errors in general then compare them for male and female students and finally to explore the effect of native and non-native English instructors on paragraph writing.

The results of this study may help researchers, teachers \& raters, and learners in writing skill or a paragraph writing specifically. To the researchers, the study may provide insights into the development of writing mysterious processes. To the teachers and the raters, the study may expect the difficult and easy aspects of paragraph writing as well as it may recommend better rubrics of how to grade paragraphs. And finally, learners will be aware of committed errors which eventually will guide them to avoid.

\section{LITERATURE REVIEW/THEORETICAL BACKGROUND}

At sentence level, Connell (2000) asked Japanese students to write grammatical and meaningful sentences. The analysis found that more errors committed in using the subject, parts of speech and word order. In his study at Chulalongkorn University, Tananart (2000) revealed that students made errors mostly in grammatical structure, in writing a paragraph $73.86 \%$, followed by errors in transitional signals $10.01 \%$, verb form errors $7.68 \%$, then word choice 6.90 and the least errors were in spelling 1.55\%. Cheng (1994)'s study analyzed six first-year English majors and three second-year English majors' errors in the English compositions at Chinese University in Beijing. The results reported that most errors were syntactic, then semantic and finally morphological errors.

In terms of paragraph organization, Liu and Wang (2011) conducted a study at Chinese University in Beijing in which they securitized errors over a longitudinal period of time shedding light on their relations with performance of students' writing in the target language. The data collected from 90 compositions produced as outcomes of three tasks given through 8 weeks administered to 30 Chinese undergraduate non-English majors was analyzed to investigate errors at paragraph level among four categories: paragraph unity, paragraph development, paragraph coherence and inconsistency in point of view. The results showed that the number of paragraph-level errors was just 105 (9\%) out of 1138 identified errors in 90 compositions. In addition, the researchers found that out of these 105 errors at paragraph level - the largest errors were in paragraph development accounted for $43 \%$, then errors in paragraph coherence $28 \%$, followed by errors in paragraph unity $18 \%$ and lastly $11 \%$ to inconsistency of point of view.

After analyzing paragraph-writing data of 70 students at First Year Translation in Bushehr University of Applied Science and Technology, Shahhoseiny (2015)'s study revealed that the total number of committed errors were 165 in total. Fifty-eight errors in topic sentence represents 81.6\%, 69 errors in supporting sentences $97.2 \%$ and 38 errors in concluding sentence calculated 53.5\%. Moreover, the one-way ANOVA analysis of these errors in paragraph writing shows that the number of errors between topic sentence and both supporting sentences and concluding sentence is not significant while it is statistically significant between supporting sentences and concluding sentence.

To investigate pre-test and post-test committed errors at paragraph level, Khansir and Ahrami (2014) compared the paragraph writing outcomes of 90 undergraduate students in Bushehr University of Medical Sciences and Health Services in pre-test and post-test after teaching students how to write a paragraph. The T-test and MC NE mar test of data revealed that students' paragraph writing in post-test was 81 errors while they were 209 errors in the pre-test, which meant students will be better when they learn the rules of paragraph writing. More specifically, this study stated a descending ranking of four paragraph categories based on the number and percentage of errors committed in each category. At the top, the errors of supporting details were 63 in pre-test and 28 in post-test. That was followed by errors of closing sentence 54 in pre-test and 22 in post-test, then errors on topic sentence 47 in pre-test and 15 in post-test and finally less committed errors were of supporting sentence 45 in pre-test and 16 in post-test.

French (2005) pointed out that for the sake of communication there is an inclination to accept errors. In addition, he found that the acceptance of errors is affected, to some extent, by negative interference of the mother tongue third person "s" article and plural errors. However, the acceptance of sentence combining, sentence fragments, omission of subject, generalizing or obscuring of subjects, and omission of expected superlatives was significant. In addition, Zhang et al (1995) investigated committed errors in multiple-choice test and an essay-writing test completed by English majors and non-English majors of a Chinese University. The results showed that non-English majors committed more errors than English majors in the writing test but they were better in the multiple choice test. Moreover, rhetorical errors were made greater than grammatical errors by both non-English majors and English majors.

As reviewed, the studies have investigated EFL students' errors in sentence structures of a paragraph, sentence connections with following sentences and paragraph organization. Moreover, the studies have examined the relationship between different variables such as learners' proficiency, paragraph writing instruction, different writing tasks and longitudinal factors and from the other side the errors that are committed in writing a paragraph. But studies that were 
hard to find are one that examine the errors at the sentence structure and the paragraph level in terms of both gender (male or female) and also the writing instructors (whether English native speakers or non-native English speakers). As well known, English language becomes an international language that is used for communications and instructions. Saudi Students at schools and universities study English as a foreign language and they have many problems in different aspects. In the paragraph writing courses, instructors in Saudi Universities find many errors that students make. Therefore, this study seeks to detect Saudi students' errors at both the sentence level and the paragraph level with shedding light on the differences in the types and frequencies of errors among male and female students and the role of the language nativity.

\section{METHODOLOGY}

\section{A. Research Questions}

The goal of this study is to answer the following questions:

1. What are the Saudi university students' types and frequencies of errors committed when writing a paragraph?

2. Are the types and frequencies of errors made by female students in paragraph-writing statistically significantly different from the types and frequencies of errors made by male students?

3. Are there statistically significant differences in the types and frequencies of errors between university students taught by English native-speaker instructors and university students taught by non-native English instructors?

\section{B. Research Objectives}

The ultimate objectives of the present study are listed below:

To identify the Saudi Prince Sattam bin Abdulaziz University students' types and frequency of errors in paragraphwriting.

To investigate if there is a difference in types and frequency of errors between male and female students in their written paragraphs

To examine if there is a difference in types and frequency of errors between students who are taught by English native-speaker instructors and students who have been taught by non-native English instructors.

\section{Hypotheses of the Study}

The study proposed the following hypotheses:

1. Students make many errors related to sentence structure, paragraph unity, paragraph development, paragraph coherence, and inconsistency of point of view.

2. There is no a statistically significant difference between male and female students in the types of errors in paragraph writing.

3. There are statistically significant differences between university students who are taught by English native-speaker instructors and university students who are taught by non-native English instructors in the type of errors in paragraph.

\section{Significance of the Study}

The results of this study could be useful for students, instructors and curriculum designers. For students, they would be vigilant of their errors in writing a paragraph which would lead to avoid committing these errors in the future. Teachers and curriculum designers would also be aware of the systematic types and frequencies of errors that students commit in paragraph-writing. Thus, they can focus on these errors in order to avoid them in the writing tasks in curricular and courses selected. In addition, they pay a considerable attention to strategies, techniques and methods that are applied to improve students' competence in paragraph-writing.

\section{E. Sample/Participants}

Participants in this study were 80 Preparatory Year i.e. foundation year students. Forty male and 40 female students aged 18 to 20 years old. The study sample in both male and female campuses were students in groups 1 thru 7 which represented high level students in general, based on placement test for the Preparatory Year admission. Half of the participants i.e. 20 students in each campus took writing course from a native speaker of English and the other half from a non-native speaker of English. The mother tongue of the non-native speaker teachers was Arabic.

\section{F. Instrument( $(s)$}

The corpus of data that is analyzed in this study is the written paragraphs of 80 participants who are studying English in their Preparatory Year program at Prince Sattam bin Abdulaziz University. The students were asked to write a paragraph about one of four topics that were general and not related to the topics covered in their writing class. The selection of the topics was based on being general and in away familiar topics to students. To confirm that these topics have not been in the material nor were used in free writing activities, teachers of the students were consulted and they helped in the selection process. Participants were asked to write about one of the following topics: A. Write about your favorite food. B. Do you prefer to live in a big city or a small town? Explain why or why not? C. What subject did you prefer in your school? Explain your preference. And question D. Why does learning a foreign language especially English become important nowadays? 


\section{G. Data Collection Procedures}

Research was conducted in the 13th week of their semester, which goes for 15 weeks in total. Subjects were handed a sheet with the four topics abovementioned. They were given 25 minutes to carefully read the topics and write a paragraph of about 100 words on only one topic out of four.

\section{Data Analysis}

The 80 collected paragraphs for the present study were analyzed based on two classifications in order to identify the errors. At the level of sentence structure, the study adopted Chanquoy (2001)'s classification that includes the following:

1. Grammatical errors: this category includes errors related to subject-verb agreement, verb tenses, gender and number, agreement of nouns, verbs and adjectives and articles.

2. Punctuation errors: it discusses the errors in using punctuations and capitalizations.

3. Spelling errors: this category deals with orthography errors in the written paragraphs.

And at the paragraph level, the present study adopted Liu, M \& Wang (2011)'s classification that includes the following:

1. Paragraph Unity errors: this category deals with errors that were committed because of a- Failing to show a controlling idea, b- Having more than one controlling idea and c- Having a topic sentence that does not really control all the ideas in the paragraph

2. Paragraph Development errors: it discusses errors that were performed because of a- Failing to supply enough explanation to a controlling topic, or a topic statement in the case of argumentative writing and b- Failing to supply the right information or related information needed to elaborate on the topic.

3. Paragraph Coherence errors: this category deals with errors that were committed because of

a. An ineffective or illogical organization of the thoughts in a paragraph and b- A failure to provide necessary or proper connecting devices between ideas.

4. Inconsistency in point of view errors: this category discusses errors committed because of the wrong shift in person, tense or number between sentences within a paragraph

Then, the identified errors were dealt with in three steps. First, the errors were classified. All types of errors and their frequencies were listed. In the next step, a comparison was made by using (Ch2) test to detect significant differences between male and female students in the types of errors in paragraph writing. Finally, a comparison was made by using (Ch2) test to detect significant differences between university students who are taught by English native-speaker instructors and university students taught by non-native English instructors.

\section{RESULTS}

In this section of the study, results and discussions are presented according to the three research raised in the current study.

\section{A. Types of Errors and Frequencies}

The aim of this section is to answer the first research question: What are the Saudi university students' types and frequencies of errors committed when writing a paragraph? The results agreed with the research hypothesis that Saudi university students both male and female commit many types of errors with varied frequencies in sentence structure, unity, development, coherence, and inconsistency of point of view when writing a paragraph. The results of types and frequencies of errors committed when writing a paragraph by 80 Saudi university students in the preparatory year at Prince Sattam bin Abdulaziz University were 1580 errors in total. Details shown below in table 1. 
TABLE I

TYPES AND FREQUENCIES OF ERRORS COMMITTED BY STUDENTS WHEN WRITING ENGLISH PARAGRAPHS

\begin{tabular}{|l|l|l|l|}
\hline No & Types of Errors & Frequencies & Percentages \\
\hline 1 & Fragment & 142 & 8.99 \\
\hline 2 & Articles & 139 & 8.80 \\
\hline 3 & Verb Tense & 64 & 4.05 \\
\hline 4 & Plurality & 55 & 3.48 \\
\hline 5 & Prepositions & 47 & 2.97 \\
\hline 6 & Parts of Speech & 40 & 2.53 \\
\hline 7 & Subject-Verb Agreement & 37 & 2.34 \\
\hline 8 & Comparison & 36 & 2.28 \\
\hline 9 & Pronouns & 32 & 2.03 \\
\hline 10 & Infinitive and Gerund & 30 & 1.90 \\
\hline 11 & Relative Clause & 21 & 1.33 \\
\hline 12 & Third Person Singular & 14 & 0.89 \\
\hline 13 & Conjunctions & 7 & 0.44 \\
\hline 14 & Negation & 2 & 0.13 \\
\hline 15 & Spelling & 234 & 14.81 \\
\hline 16 & Punctuation & 255 & 16.14 \\
\hline 17 & Capitalization & 161 & 10.19 \\
\hline 18 & Paragraph Unity & 60 & 3.80 \\
\hline 19 & Paragraph Development & 81 & 5.13 \\
\hline 20 & Paragraph Coherence & 77 & 4.87 \\
\hline 21 & Inconsistence of Point of View & 46 & 2.91 \\
\hline & Total & 1580 & 100.00 \\
\hline & & \\
\hline
\end{tabular}

As shown in Table 1, the results show that students at Prince Sattam bin Abdulaziz University made many errors at both the sentence and the paragraph levels in writing English paragraphs. The errors at the sentence level include these types: Fragments, articles, verb tense, plurality forms, prepositions, parts of speech, subject-verb agreement, comparison, infinitive and gerund, relative clauses, third person singular, conjunctions and negation and also the errors in spelling, punctuations, and capitalization. At the paragraph level, the participants committed many errors in the types of paragraph unity, paragraph development, paragraph coherence and inconsistency of point of view by shifting in person, number or tense.

To give a clear explanation, figure 1 represents the percentages of each type of errors that have committed when writing English paragraphs.

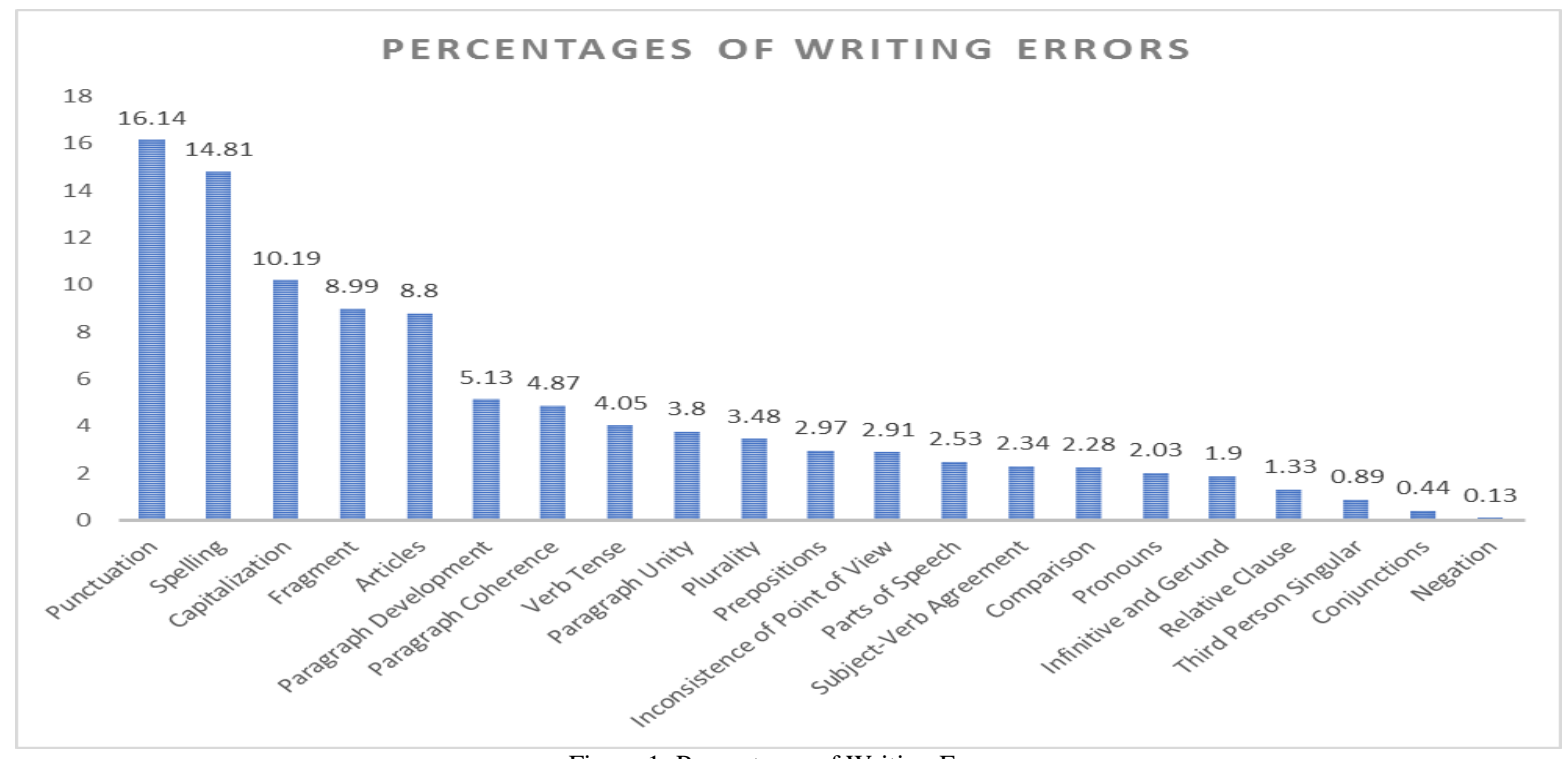

Figure 1: Percentages of Writing Errors

As shown in figure 1, the results show that the errors that have been made by Prince Sattam bin Abdulaziz University students at the preparatory year are the following in descending order: punctuation (16.4\%), spelling (18.81\%), capitalization $(10.19 \%)$, fragment $(8.99 \%)$, articles $(8.8 \%)$, paragraph development $(5.13 \%)$, paragraph coherence $(4.87 \%)$, verb tense $(4.05 \%)$, paragraph unity $(3.8 \%)$, plurality $(3.48 \%)$, prepositions $(2.97 \%)$, inconsistency of point of view $(2.91 \%)$, parts of speech $(2.53 \%)$, subject-verb agreement $(2.34 \%)$, comparison $(2.28 \%)$, pronouns $(2.03 \%)$, infinitive and gerund $(1.9 \%)$, third person singular $(0.89 \%)$, conjunctions $(0.44 \%)$ and negation $(0.13 \%)$. The majority of errors students committed at the sentence level which reflects the need to pay special attention to write a sentence in classrooms. The number of the errors at the sentence level that includes all grammatical errors adding to the errors of spelling, punctuation, and capitalization was 1316 in total accounted for 83.29\%. On the other hand, at the paragraph 
level that includes paragraph unity, paragraph development, paragraph coherence and inconsistency of point of view, the participants committed 264 errors accounted for $16.70 \%$ of all the errors. It is very important to note that the largest percentage of errors at the paragraph level was errors in paragraph development 5.13\%, and then errors in paragraph coherence $4.87 \%$ followed by errors in paragraph unity $3.80 \%$ and inconsistency of point of view $2.91 \%$.

\section{B. Comparison between Saudi Male and Female University Students' Writing Errors}

This section gives an answer to the second research study: Are the types and frequencies of errors made by female students in paragraph writing statistically significantly different from the types and frequencies of errors made by male students? The results confirmed the research hypothesis (2) except for errors in grammar in which there are no statistically significant differences between male and female students. In the following, table (2) presents the differences in types and frequencies of errors committed by Saudi male and female university students.

TABLE II

TyPES AND FREQUENCIES COMMITTED By MALE AND FEMALE STUDENTS WHEN WRITING ENGLISH PARAGRAPH

\begin{tabular}{|l|l|l|l|l|l|}
\hline No & Types of Writing Errors & \multicolumn{2}{|l|}{ Frequencies of Errors } & \multicolumn{2}{l|}{ Percentages } \\
\hline & & Male & Female & Male & Female \\
\hline 1 & Grammar & 389 & 277 & 46.75 & 37.03 \\
\hline 2 & Spelling & 127 & 107 & 15.26 & 14.30 \\
\hline 3 & Punctuation & 114 & 141 & 13.70 & 18.85 \\
\hline 4 & Capitalization & 79 & 82 & 9.50 & 10.96 \\
\hline 5 & Paragraph Unity & 27 & 33 & 3.25 & 4.41 \\
\hline 6 & Paragraph Development & 39 & 42 & 4.69 & 5.61 \\
\hline 7 & Paragraph Coherence & 35 & 42 & 4.21 & 5.61 \\
\hline 8 & Inconsistency of Point of View & 22 & 24 & 2.64 & 3.21 \\
\hline 9 & Total & 832 & 748 & 100 & 100 \\
\hline
\end{tabular}

As illustrated in table 2, there are differences in frequencies of errors made by male and female students. At the sentence level, female students made fewer errors than the male students except for punctuation and capitalization. Male students committed 389 errors in grammar while female students committed 277 errors. Errors in spelling were 127 by males but 107 errors by females. Males made fewer errors in punctuation i.e. 114 errors than females who made 141 errors, and capitalization ( 79 by the males and 82 by the females). At the paragraph level, males committed fewer number of errors than that committed by females students; in paragraph unity, males 27 while females 33, in paragraph development, males 39 while females 42 , in paragraph coherence, males 35 while females 42 , and in inconsistency of point of view, males 22 while females 24 errors.

To investigate whether the differences are statistically significant or not in the types of errors in paragraph writing between male and female students, $\left(\mathrm{Ch}^{2}\right)$ test was conducted (see table 3 ).

TABLE 3

THE RESULTS OF (CH2) FOR DIFFERENCES BETWEEN MALE AND FEMALE STUDENTS IN THE TYPES OF ERRORS IN PARAGRAPH WRITING

\begin{tabular}{|c|c|c|c|c|}
\hline Types of errors & Gender & Frequencies & $\mathrm{Ch}^{2}$ & Sig \\
\hline \multirow{3}{*}{ Grammar } & Male & 389 & \multirow{3}{*}{18.835} & \multirow{3}{*}{0.00} \\
\hline & Female & 277 & & \\
\hline & Total & 666 & & \\
\hline \multirow{3}{*}{ Spelling } & Male & 127 & \multirow{3}{*}{1.709} & \multirow{3}{*}{0.191} \\
\hline & Female & 107 & & \\
\hline & Total & 234 & & \\
\hline \multirow{3}{*}{ Punctuation } & Male & 114 & \multirow{3}{*}{2.859} & \multirow{3}{*}{0.091} \\
\hline & Female & 141 & & \\
\hline & Total & 255 & & \\
\hline \multirow{3}{*}{ Capitalization } & Male & 79 & \multirow{3}{*}{0.056} & \multirow{3}{*}{0.813} \\
\hline & Female & 82 & & \\
\hline & Total & 161 & & \\
\hline \multirow{3}{*}{ Paragraph Unity } & Male & 27 & \multirow{3}{*}{0.600} & \multirow{3}{*}{0.439} \\
\hline & Female & 33 & & \\
\hline & Total & 60 & & \\
\hline \multirow{3}{*}{$\begin{array}{l}\text { Paragraph } \\
\text { Development }\end{array}$} & Male & 39 & \multirow{3}{*}{0.111} & \multirow{3}{*}{0.739} \\
\hline & Female & 42 & & \\
\hline & Total & 81 & & \\
\hline \multirow{3}{*}{$\begin{array}{l}\text { Paragraph } \\
\text { Coherence }\end{array}$} & Male & 35 & \multirow{3}{*}{0.636} & \multirow{3}{*}{0.425} \\
\hline & Female & 42 & & \\
\hline & Total & 77 & & \\
\hline \multirow{3}{*}{$\begin{array}{l}\text { Inconsistency of } \\
\text { Point of View }\end{array}$} & Male & 22 & \multirow{3}{*}{0.087} & \multirow{3}{*}{0.768} \\
\hline & Female & 24 & & \\
\hline & Total & 46 & & \\
\hline
\end{tabular}

Table (3) shows that:

- There are statistically significant differences between male and female students in Grammar; where $\left(\mathrm{Ch}^{2}\right)$ value reached (18.835) at the sig (0.00) in favor of male students (389) in comparison to 277 for the females. 
- There are no statistically significant differences between male and female students in Spelling, Punctuation, Capitalization, Paragraph Unity, Paragraph Development, Paragraph Coherence, and Inconsistency of Point of View where $\left(\mathrm{Ch}^{2}\right)$ values don't reach a statistically significant level.

\section{A Comparison between Writing Errors of Students Taught by English Native-speaker Instructors and University Students Taught by Non-native English Instructors}

This section of the study deals with the third research study question: Are there statistically significant differences in the types and frequencies of errors between university students taught by English native-speaker instructors and university students taught by non-native English instructors? The results partially agreed with the third hypothesis that proposed there are statistically significant differences between university students taught by English native-speaker instructors and university students taught by non-native English instructors in some types of errors in paragraph writing, namely grammar, spelling and punctuation. Table (4) below illustrated the results of the third research question.

TABLE IV

TyPES AND FrequenCIES OF ERRORS COMMITTED By STUDENTS WHO TAUGHT By NATIVE AND NON-NATIVE TEACHERS WHEN WRITING ERRORS

\begin{tabular}{|c|c|c|c|c|c|}
\hline No & Types of Errors & \multicolumn{2}{|c|}{ Frequencies } & \multicolumn{2}{|c|}{ Percentages } \\
\hline & & By N & By Non-N & By N & By Non-N \\
\hline 1 & Grammar & 303 & 363 & 42.14 & 42.16 \\
\hline 2 & Spelling & 102 & 132 & 14.19 & 15.33 \\
\hline 3 & Punctuation & 119 & 136 & 16.55 & 15.80 \\
\hline 4 & Capitalization & 64 & 97 & 8.90 & 11.27 \\
\hline 5 & Paragraph Unity & 33 & 27 & 4.59 & 3.14 \\
\hline 6 & Paragraph Development & 37 & 44 & 5.15 & 5.11 \\
\hline 7 & Paragraph Coherence & 39 & 38 & 5.42 & 4.41 \\
\hline 8 & Inconsistency of Point of View & 22 & 24 & 3.06 & 2.79 \\
\hline & Total & 719 & 861 & 100 & 100 \\
\hline
\end{tabular}

*By N= Student Taught by Native English Teachers

*By Non-N= Students Taught by Non-Native English Teachers

As shown in table 4, students who were taught English native-speaker instructors committed fewer errors at the sentence level: 303 in grammar, 102 in spelling, 119 in punctuation and 64 in capitalization. On contrary, these errors were 363 in grammar, 132 in spelling, 136 in punctuation and 97 in capitalization for students who were taught by nonnative English instructors. The results at the paragraph level showed that students who were taught by native English teachers made fewer frequencies in paragraph development (37 errors) and inconsistency of point of view (22 errors) in comparison to students taught by non-native English instructors who made 44 errors in paragraph development and 24 errors in inconsistency of point of view. On the other hand, students who were taught by native-speaker instructors made higher error frequencies in paragraph unity (33 errors) and paragraph coherence (39 errors) in contrast to students taught by non-native English teachers who made 27 errors in paragraph unity and 38 errors in paragraph coherence.

To investigate for statistically significant differences in the types of errors between university students taught by English native-speaker instructors and university students taught by non- native English instructors, $\left(\mathrm{Ch}^{2}\right)$ test was used; table (5) below. 
TABLE 5

THE RESULTS OF (CH2) FOR DIFFERENCES BETWEEN UNIVERSITY STUDENTS TAUGHT BY ENGLISH NATIVE AND NON-NATIVE INSTRUCTORS IN THE TYPES OF ERRORS IN PARAGRAPH WRITING

\begin{tabular}{|c|c|c|c|c|}
\hline Types of errors & Gender & Frequencies & $\mathrm{Ch}^{2}$ & Sig \\
\hline \multirow{3}{*}{ Grammar } & Native & 303 & \multirow{3}{*}{5.405} & \multirow{3}{*}{0.020} \\
\hline & Non- native & 363 & & \\
\hline & Total & 666 & & \\
\hline \multirow{3}{*}{ Spelling } & Native & 102 & \multirow{3}{*}{3.846} & \multirow{3}{*}{0.050} \\
\hline & Non- native & 132 & & \\
\hline & Total & 234 & & \\
\hline \multirow{3}{*}{ Punctuation } & Native & 119 & \multirow{3}{*}{1.133} & \multirow{3}{*}{0.287} \\
\hline & Non- native & 136 & & \\
\hline & Total & 255 & & \\
\hline \multirow{3}{*}{ Capitalization } & Native & 64 & \multirow{3}{*}{6.764} & \multirow{3}{*}{0.009} \\
\hline & Non- native & 97 & & \\
\hline & Total & 161 & & \\
\hline \multirow{3}{*}{$\begin{array}{l}\text { Paragraph } \\
\text { Unity }\end{array}$} & Native & 33 & \multirow{3}{*}{0.600} & \multirow{3}{*}{0.439} \\
\hline & Non- native & 27 & & \\
\hline & Total & 60 & & \\
\hline \multirow{3}{*}{$\begin{array}{l}\text { Paragraph } \\
\text { Development }\end{array}$} & Native & 37 & \multirow{3}{*}{0.605} & \multirow{3}{*}{0.437} \\
\hline & Non- native & 44 & & \\
\hline & Total & 81 & & \\
\hline \multirow{3}{*}{$\begin{array}{l}\text { Paragraph } \\
\text { Coherence }\end{array}$} & Native & 39 & \multirow{3}{*}{0.013} & \multirow{3}{*}{0.909} \\
\hline & Non- native & 38 & & \\
\hline & Total & 77 & & \\
\hline \multirow{3}{*}{$\begin{array}{l}\text { Inconsistency } \\
\text { of Point of } \\
\text { View }\end{array}$} & Native & 22 & \multirow{3}{*}{0.087} & \multirow{3}{*}{0.768} \\
\hline & Non- native & 24 & & \\
\hline & Total & 46 & & \\
\hline
\end{tabular}

Table (5) shows that:

- There are statistically significant differences between university students who are taught by English native-speaker instructors and university students who are taught by non-native English instructors in the type (Grammar); where $\left(\mathrm{Ch}^{2}\right)$ value reached (5.405) with sig (0.020) in favor of Non- native (363) and the native was (303).

- There are statistically significant difference between university students taught by English native-speaker instructors and university students taught by non-native English instructors in the type of errors (Spelling); where $\left(\mathrm{Ch}^{2}\right)$ value reached (3.846) at the sig (0.050) in favor of Non- native (132) and the native was (102).

- There are statistically significant differences between university students who are taught by English native-speaker instructors and university students who are taught by non-native English instructors in the type of errors in paragraph writing (Capitalization); where $\left(\mathrm{Ch}^{2}\right)$ value reached (6.764) at the sig (0.009) in favor of Non- native (97) and the native was (64).

- There is no statistically significant differences between university students taught by English native-speaker instructors and university students taught by non-native English instructors in the types of errors (Punctuation, Paragraph Unity, Paragraph Development, Paragraph Coherence, Inconsistency of Point of View); where $\left(\mathrm{Ch}^{2}\right)$ values do not reach a statistically significant level

\section{DISCUSSION}

The current study sought to investigate and classify the exact types and frequencies of errors committed in paragraph writing by 80 students at the Preparatory Year Deanship at Prince Sattam bin Abdulaziz University during the first semester 2017-2018. In addition, it identified the differences between male and female students in one side and the differences between the students taught by native or non-native English instructors. The results of this study show that Saudi students who learn English as a foreign language are not efficient enough in dealing with the rules of writing an English sentence or an English paragraph. The study agrees with Hammad (2012) who considered one of the most important reasons for committing errors in writing is the lack of exposure to English input. Students in Saudi Arabia learn English as a foreign language in schools and universities. The majority of the Saudi students do not have an environment that is conducive to using English which facilitates forgetting the English rules. That goes in line with Latif (2007) who points out that an insufficient knowledge of a foreign language structure is the main source for committing errors in writing.

Some types of errors identified in this study such as fragments, errors in articles, and errors in prepositions reflect the effect of the rules of the students' mother tongue. Al-Khasawneh (2014) points out that language interference and negative transfer of the mother language cause errors in EFL paragraph writing. Moreover, some paragraph writing errors especially those related to the paragraph level such as paragraph development are caused by ineffective methodologies and strategies of teaching paragraph writing. Some teachers focus on explaining grammatical rules in traditional methods that depend on repetition and using grammar in separate sentences, not in communicative methods which motivates students to use grammar in an interactive way. This strategy of teaching grammar rules enables the learners to produce simple sentences but it does not help enough in writing a compound and complex sentences. These 
instructors pay little attention to the other rules in writing a well-structured paragraph. The methodology of teaching writing a paragraph must go over enough time on provoking the students to think freely and provide ideas about the topic. This should be followed by training them to use an effective and logical organization of thoughts. Instructors should also pay special attention to teaching students how to show a single clear controlling idea in the paragraph, supply the right and related ideas required to elaborate on the topic, shift correctly in person, tense and number between the sentences within a paragraph. The largest percentage of errors was in paragraph development followed by paragraph coherence then paragraph unity and finally inconsistence of point of view that agreed with previous studies like that of (Liu \& Wang, 2011). In fact, many students wrote correct topic sentences, but they could not develop or support them with other ideas, details, and examples. Instructors of writing should adopt a methodology of teaching writing a paragraph that confirms correct grammar, vocabulary, spelling, punctuation, and capitalization. Furthermore, instructors of writing should give students enough time of practice to formulate and write the controlling idea and develop it coherently and close the paragraph with a reasonable conclusion.

Moreover, the results of Saudi university students in EFL paragraph writing show that gender makes no difference. The statistical analysis of the committed errors in 80 paragraphs reveals that there is no significant difference between male and female students in the types and frequencies of errors in paragraph writing except for the type of errors in grammar. In errors of grammar, the value of (Ch2) reached (18.835) at the sig (0.000) in favor of male students (389); the female students' was (277). This difference could have been caused by the extent of exposure and use English inside and outside of classrooms and teacher's methodology. Therefore, both male and female students require a lot of practice and guidance in their composition. In fact, there is a need for a future study to scrutinize the differences in male and female students' writings focusing especially on syntactic complexity, paragraph unity and ways of developing ideas.

In the third research question, this study contributes to the assumption that native English teachers have unproved superiority over non-native English teachers in EFL teaching (Walkinshaw \& Oanh, 2014). The results confirm that there are no significant differences in five types of errors: punctuation, paragraph unity, paragraph development, paragraph coherence, and inconsistency of point of view. The statistically significant differences were in grammar and spelling which indicate the advantage of native English instructors in paragraph writing, but the significant difference in capitalization reveals that the students who were taught by non-native English teacher committed fewer errors than the students who were taught by native English teachers. The current study agrees with the claim that non-native teachers have advantages in EFL teaching and learning and there is no mean to decide conclusively the absolute superiority of native teachers (Merino, 1997). Finally, it is noteworthy to confirm that more studies toward native and non-native issue are very necessary.

\section{CONCLUSIONS}

The present study examined the sentence-level and the paragraph-level errors in 80 written paragraphs by Saudi undergraduate university students at Prince Sattam bin Abdulaziz University in the first semester of 2017-2018. The analysis yielded 1580 composition errors. At the sentence-level, errors in punctuation counted for the largest percentage, followed by spelling, capitalization, fragment, articles, verb tense, plurality, prepositions, parts of speech, subject-verb agreement, comparison, pronouns, infinitive and gerund, third person singular, conjunctions, and negation. Errors in paragraph development accounted for the largest percentage at the paragraph-level, followed by paragraph coherence, paragraph unity, and inconsistency of point of view. As mentioned before, the identified errors at the sentence-level accounted for $83,29 \%$ of the total number of errors in the 80 English paragraphs. Thus, methodologies of teaching paragraph writing should provide an intensive training on English rules in communicative and interactive ways. And to reduce errors at the paragraph-level, curriculum designers and instructors of writing should use many tasks that help the students support their ideas grammatically and logically.

Meanwhile, the findings of this study reveal two further results. Except for the errors in grammar, the study does not detect significant difference between male and female students in the types and frequencies of committed errors in the 80 paragraphs collected from undergraduate students in the preparatory Year Deanship at Prince Sattam bin Adulaziz University. The other one is that native English instructors cannot be granted superiority in teaching writing. Non-native English instructors have also shown better results in teaching writing to EFL students in teaching writing in the foreign or second language. In fact, further studies are required to probe the differences in compositions between male and female students and to examine further the superiority of native language instructors.

\section{REFERENCES}

[1] Al-Khasawneh, F. (2014). Error Analysis of Written English Paragraphs by Jordanian Undergraduate Students: A Case Study. International Journal of English Language, Literature and Humanities, 2.8, 85-100.

[2] Chanquoy, L. (2001). How to make it easier for children to revise their writing: A study of text revision from 3rd to 5th grades. British Journal of educational psychology, 71.1, 15-41.

[3] Cheng, J. (1994). On the teaching of English writing. Foreign Language Teaching and Research, 98.2, 12-18.

[4] Connell, P. (2000). A technique for examining the severity of student errors in communicative English. The English Teacher, $3.2,95-103$. 
[5] Corder, S. P. (1967). The significance of learner's errors. IRAL-International Review of Applied Linguistics in Language Teaching, 5.1-4, 161-170.

[6] French, G. (2005). The cline of errors in the writing of Japanese university students. World Englishes, 24.3, 371-382.

[7] García Merino, I. (1997). Native English-speaking teachers versus non-native English-speaking teachers. Revista alicantina de estudios ingleses, 10, 69-79.

[8] Hammad, E. A. R. (2012). Teaching and learning English reading in Gaza prep school: A descriptive study. PhD dissertation, Cairo University, Egypt.

[9] James, C. (2013). Errors in language learning and use: Exploring error analysis. London: Routledge.

[10] Jayakaran, L. (2005). Everyone's Guide to effective writing. India: Chennai, 2M International.

[11] Khansir, A., \& Ahrami, M. (2014). Error Analysis and Paragraph Writing. Language in India, 14.9, 74-162.

[12] Latif, M. A. (2007). The factors accounting for the Egyptian EFL university students' negative writing affect. Essex Graduate Student Papers in Language \& Linguistics, 9.7, 57-82.

[13] Liu, M., \& Wang, G. (2011). Paragraph-level Errors in Chinese Undergraduate EFL Learners 'Compositions: A Cohort Study. Theory and Practice in Language Studies, 1.6, 584-593.

[14] Norrish, J. (1983). Language learners and their errors. London: Macmillan.

[15] Shahhoseiny, H. (2015). A study of errors in the paragraph writing of EFL learners: A case study of first year translation students at University of Applied Science and Technology in Bushehr, Iran. Theory and Practice in Language Studies, 5.6, $1307-1312$

[16] Tananart, O. (2000). The Survey of Errors in Written Work of Students Learning Fundamental English at Chulalongkorn University. Passa Paritasna, 18, 87-101.

[17] Walkinshaw, I., \& Oanh, D. H. (2014). Native and non-native English language teachers: Student perceptions in Vietnam and Japan. Sage Open, 4.2, 1-9.

[18] Zhang, Z. (1995). Major issues in the teaching of English writing in China. Foreign Language Teaching and Research, 4, 4349.

Farooq A. AlTameemy was born in Yemen in 1971. He received his MA in Linguistics (TESL) \& Phd in Curriculum, Instruction, and Media Technology (Language Education), from Indiana State University, USA in 2010.

$\mathrm{He}$ is currently the Head of the English Dept., Preparatory Year Deanship, at Prince Sattam Bin Abdulaziz University, Saudi Arabia. His research interests include EFL/ESL issues and using technology in language teaching.

Dr Farooq AlTameemy is a Fulbright Alumni.

Amer Daradkeh was born in Jordan in 1983. He received his M.A. in applied linguistics, from Mutah University, Jordan in 2009.

He is currently an instructor of English, Preparatory Year Deanship, at Prince Sattam Bin Abdulaziz University, Saudi Arabia. His research interests include EFL/ESL issues and language acquisition. 